Ciudad y territorio 


\section{Paisaje hídrico y sostenibilidad urbana}

Dr. Mario Esteban del Castillo Oyarzún, Arquitecto

Invitado internacional

Universidad Católica de Chile

mdelcastillo@uc.cl

Dra. Claudia Andrea Castillo Haeger, Arquitecta

Invitada internacional

Universidad Diego Portales UDP. Chile

claudia.castillo@udp.cl

Recibido: agosto del 2015

Aceptado: mayo del 2016

Ciudad y territorio

Investigación 


\section{Resumen}

La ciudad debe ser reconocida como parte de la naturaleza y diseñada, en consecuencia, comprendiendo las conexiones entre paisaje y ciudad que son funcionales, sostenibles, signi cantes y poseedores de arte y belleza. El paisaje urbano se constituye de formas que conjugan naturaleza, historia y cultura, poniendo en valor la complejidad de variables teóricas y prácticas que implican biodiversidad, procesos eco sistémicos y diversas actividades humanas en el tiempo. En ese contexto, una de las coordenadas especialmente valiosas y presentes en el paisaje urbano de muchas de las ciudades de Chile se construye a partir del trazado que ha hecho el agua. Entonces, reconocer el paisaje urbano como una relación de diseño sobre el paisaje hídrico de soporte, resulta indispensable para entender la ciudad y sus dinámicas de transformación como un todo fluido y en movimiento. Este trabajo busca proponer un sustrato teórico, un imaginario práctico y una metodología posible para la configuración de paisajes hídricos urbanos para aportar en la discusión de cómo enfrentaremos la condición hídrica en nuestras ciudades contemporáneas en el marco del quinto paradigma de la urbanización en conjunto con el enfoque de ciudades sensibles al agua.

Palabras clave: paisaje urbano; ríos urbanos; urbanismo sustentable.

\section{Abstract}

The city should be recognized as part of nature and, consequently, be designed with an understanding of the relationships between the landscape which are functional, sustainable, meaningful, and possess art and beauty. The urban landscape is composed of forms which interplay nature, history and culture, emphasizing the complexity of theoretical and practical variables associated with bio-diversity, ecosystemic processes, and diverse human activities over time. In this context, one especially valuable dimension present in many Chliean cities can be constructed on the basis of the course taken by water. The recognition of urban landscape as a relationship between its design and its supporting hydric landscape is indispensable for understanding the city and the dynamics of its transformation as a fluid in movement. This article seeks to propose a possible theoretical, practical and methodological basis for comprehending the configuration of urban hydric landscapes in contemporary cities in the framework of the fifth paradigm of urbanization focused on water sensitive cities.

Keywords: urban landscape; urban rivers; sustainable urbanism. 


\title{
Paisaje hídrico y sostenibilidad urbana
}

\author{
Mario Esteban del Castillo Oyarzún ${ }^{1}$
}

Claudia Andrea Castillo Haeger ${ }^{2}$

\section{Introducción: Paisaje urbano y el quinto paradigma de la urbanización, una lectura contemporánea}

Los sistemas de conexiones físicas, naturales o artificiales, entre las ciudades y sus fuentes hídricas han cambiado a través del tiempo. También lo han hecho nuestros modelos conceptuales para entender dichos sistemas y nuestro entendimiento de cómo deberían funcionar y relacionarse. Existen, al menos, cuatro modelos históricos reconocibles de paradigmas que reflejan la evolución y desarrollo de las fuentes hídricas urbanas, y estamos asistiendo a la emergencia de un nuevo "quinto paradigma" (Novotny \& Brown, 2007, p. 13).

El primer paradigma suponía la dependencia de las antiguas ciudades de pozos para el abastecimiento de agua, de cuerpos de agua superficiales para suplir necesidades funcionales como transporte, irrigación y limpieza y de las calles para la disposición de residuosydrenajes. El segundo paradigma surgecuandolas ciudades antiguas comienzan a crecer a la vez que la demanda por agua, y cuando las fuentes superficiales accesibles se hacen insuficientes. Este paradigma se caracterizaba por la utilización de modelos ingenieriles para la captación, conducción y almacenamiento de agua. A este paradigma corresponde la invención de las alcantarillas. El tercer paradigma surge para enfrentar los asuntos relacionados con las aguas urbanas y las aguas servidas, y se caracterizó por inversiones masivas en control y tratamiento en fuentes de contaminación resultantes de la combinación o separación de sistemas de conducción de aguas; surge a comienzos del siglo XX, a raíz de la eclosión de enfermedades epidémicas transmitidas por el agua. El cuarto paradigma instala la necesidad de establecer control sobre fuentes difusas, no puntuales de contaminación del agua urbana en la red de distribución y conducción, como el caso de las escorrentías urbanas. Como resultado de estas preocupaciones, a fines del siglo XX el parlamento Europeo ponía en actas su Water Framework Directive mientras que los Estados Unidos aprobaban su Clean Water Act. Ambos documentos buscan establecer protocolos e iniciativas para la protección y manejo de las aguas urbanas. 
El quinto paradigma surge junto con el Informe Brundtland para Naciones Unidas, Our Common Future de 1987. Este paradigma busca la sostenibilidad hídrica y ecológica de las ciudades del futuro. Se trata de un paradigma que adopta un enfoque holístico y sistémico por sobre el enfoque funcional en componentes individuales, característico de los modelos antiguos. En este paradigma se consideran asuntos tan relevantes como el cambio climático, crecimiento de la población, ética y propiedad de suelo, sobreuso de las aguas urbanas y el endurecimiento del paisaje urbano (Novotny \& Brown, 2007, p. 15).

Este quinto paradigma supone la recuperación de conceptos y enfoques claros a la tradición de lo que varios autores han definido como urbanismo ecológico, que no es otra cosa que entender y diseñar lo urbano fundado sobre una tradición que se remonta a los inicios de la disciplina de la planificación urbana, en el siglo XIX.

Por otra parte, es dentro de este quinto paradigma donde tenemos una nueva oportunidad de poner el énfasis en el diseño del espacio urbano y su relación con su paisaje hídrico, además de atender la urgencia de resolver problemas funcionales del sistema hídrico de las ciudades.

Se trata de evitar la parálisis en el momento de leer el paisaje urbano y su componente profundo. Se trata de comprender un paisaje "en el que naturaleza y artificio aparecen mezclados y envueltos por un mundo vectorial y telemático: el jardín moderno" (Abalos, 2005, p.144).

Este trabajo es un ejercicio eidético, en el sentido que define James Corner, para referirse a una investigación y construcción gráfica que responde a una concepción compleja del paisaje que puede ser fotografiada y graficada, y que contiene un rango de ideas que se originan en la creatividad humana. Estas construcciones gráficas materializan las condiciones en que la realidad se conceptualiza y representa, generando, desarrollando y participando en la aparición de "realidades emergentes" (Corner, 1999, p. 153; Magrini et al., 2013), que en este trabajo, serían los paisajes hídricos urbanos contemporáneos. 


\section{Marco Teórico: La persistencia de las ideas}

\section{Idea uno: el contexto multicapa}

A mediados de la década del 2000, en el ámbito académico anglosajón se propuso el término landscape urbanism para comprender el medio urbano como una ecología donde la relación e "interacción entre artificio y naturaleza es el foco analítico y proyectual" (Abalos, 2005, p.45). Sin embargo, el biólogo Patrick Geddes, casi un siglo antes, en 1915, entiende la ciudad y su entorno como un todo orgánico en evolución, cuyo planeamiento debería basarse en la comprensión de su historia cultural y natural, y además, en sus procesos vitales contractuales. Geddes defendía el realizar estudios regionales acerca de cómo son las cosas y cómo evolucionan hacia lo que deberían ser, para informar planes urbanos y el diseño de ciudades, para ajustarlos a las particularidades sociales y geográficas. En la misma línea, Ian McHarg más adelante afirmará: "Aceptemos la proposición de que lo natural (la naturaleza) es un proceso que interactúa, que responde a leyes y que representa valores y oportunidades para uso humano con ciertas limitaciones e incluso, prohibiciones" (McHarg, 2000, p. 07), dejando en evidencia la noción de que lo urbano debe ser modelado en relación y consonancia con el soporte natural sobre el que yace.

Como Geddes, McHarg afirma que cualquier lugar "sólo puede ser comprendido a través de su evolución física" (McHarg, 2000, p. 175). Así, como prerrequisito ineludible para el planeamiento y el diseño de la ciudad, McHarg defiende la consulta del inventario ecológico, una lista que se podría aplicar a todo lugar, escala y uso de suelo: Clima, Geología, Hidrología, Limnología, Suelos, Vegetación y Vida salvaje. El inventario ecológico de McHarg es una lista de chequeo de sistemas inter relacionados, muy útil no sólo para comprender cómo podría llegar a ser un lugar, sino como herramienta de diagnóstico con la que identificar problemas y oportunidades, el diseño se convierte entonces en una estrategia evolutiva multicapa, "una herramienta de adaptación" (Whiston Spirn, 2011, p. 08).

\section{Idea dos: la complejidad natural-artificial}

La definición contemporánea de Ecosistema corresponde al botánico inglés Sir Arthur Tansley quien acuña el concepto en 1935. Tansley argumentaba que la actividad humana se encuentra dentro de los factores que determinan la estructura, función y extensión espacial del ecosistema (ecotopo). A partir de ahí, se acuñará el concepto de ecosistema humano que elimina la dicotomía humano/naturaleza (o artificial/natural) 
sobre la premisa de que todas las especies están ecológicamente integradas unas con otras, así como con los componentes abióticos de su biotopo (Tansley, A., 1935). En el ámbito urbano, tanto para Jane Jacobs como para McHarg y Kevin Lynch, "los humanos son parte de la naturaleza, como también lo son las ciudades" [...] "La naturaleza, sentimentalizada y considerada como la antítesis de la ciudad, aparentemente es entendida y asumida como pasto, aire fresco y poco más [...] y es esta lúdica falta de respeto lo que supone la devastación de la propia naturaleza" (Jacobs, 2011, p. 485). Jacobs entiende la ciudad como hábitat humano y al diseño urbano como el camino para soportar y satisfacer las necesidades humanas. Jacobs defiende un enfoque ecológico para el diseño y manejo de las ciudades argumentando que estos son problemas de organización de la complejidad (problemas de complejidad organizada) parecidos a los de los organismos vivos y que hay lecciones de diseño urbano en el estudio de los sistemas donde "muchos individuos van cambiando simultáneamente, interconectados de diversas y sutiles maneras" (Jacobs, op.cit).

Un poco más adelante, en su libro de 1984, "El Jardín de Granito: Naturaleza Urbana y Diseño Humano", Anne Whiston Spirn hacía una revisión de la literatura científica existente para argumentar que las ciudades son parte del mundo natural y consecuentemente aplicaba el cuerpo de conocimiento disponible para demostrar cómo se puede diseñar ciudad en concordancia con los procesos naturales. Organizado en secciones, aire, tierra, agua, vida y ecosistemas, el libro proponía algunos principios para el diseño ecológico de ciudades, ilustrado por casos referenciales a escala de jardín, casa, barrio, ciudad y región (Whiston Spirn, 1984, p. 35). Spirn plantea que las poéticas de la ciudad y la naturaleza podrían fusionar funciones, sentimientos y significados. Se trata de una fusión en la que el Paisaje es el hogar material (Whiston Spirn, 1988, p. 76).

\section{Idea tres: urbanismo ecológico, paisaje y construcción eidética}

La evolución del pensamiento y las apremiantes condiciones económicas y ecológicas observadas en las últimas décadas, el crecimiento geométrico de la población mundial, la migración continua desde el campo a las ciudades en conjunto con la creciente explotación de los recursos limitados del planeta, hacen que cada año más ciudades comiencen a sentir los impactos de la situación. Sin embargo, la creciente preocupación por estos temas va acompasada de una igualmente creciente dosis de escepticismo y resistencia (Mostafavi \& Gareth, 2013, p. 115). Las respuestas a estas problemáticas complejas requieren de una visión centrada en el lugar de las relaciones complejas que las generan, las ciudades, que requieren un marco complejo de respuesta informado en 
la tradición y en la innovación, marco que está encontrando su materialización natural en el urbanismo ecológico.

La ecología, tanto urbana como del paisaje, ofrecen algunas formas de pensar el objeto en estudio que suponen, a su vez, nuevas formas de actuación proyectual, ajenas a los modelos tradicionales, dando origen a nuevos modelos que pueden oxigenar a un (actualmente) debilitado concepto de sostenibilidad sin definición precisa, que en la práctica casi equivale a un cambiar todo para que nada cambie (Abalos, 2005, p.46). Sin embargo, sostenibilidad supone comprensión en diferentes niveles temporales (corto, mediano y largo plazo) y escalares (reconocer las interdependencias entre una escala cercana, media y mayor, una habitación, edificio, barrio, ciudad, territorio, región, etc.) y en diversos contextos de organización económica, histórico-cultural, socialy ambiental a fin de promover conciencia crítica, reflexión de interdependencias y responsabilidad (Briones et al, 2013). Desde el urbanismo, la heterogeneidad y complejidad urbana es rasgo característico de la ciudad y esencial frente a la sostenibilidad. Mumford ya puntualizaba que las comunidades auténticamente humanas deben preservar tanto la variedad social como la visual (Mumford, 1960). Es decir, si se disminuye la complejidad urbana, se pierden algunos de los rasgos propios de la comunidad.

Por su parte, el paisaje es un constructo cultural que no es otra cosa que la transformación de un orden natural en un paisaje cultural en el que se plasman valores y sentimientos (Nogué, 2007). El paisaje está lleno de lugares que materializan experiencias, aspiraciones y constituyen una mirada que busca transmitir una determinada forma de apropiación del espacio que se lleva a cabo de manera colectiva (op.cit.). En esa línea discursiva, el paisaje urbano no será comprendido en su totalidad si se le observa solo desde su coordenada material. El leer el paisaje urbano desde lo material invisibilizará una parte relevante y esencial del paisaje (Lousiet, 2001). Es necesario considerar lo que se ha invisibilizado, lo intangible (op.cit.). El visibilizar lo que se ha dejado fuera de foco implica ser consecuente con el argumento de que el paisaje es una construcción social en la que el sujeto no puede quedar al margen. Y esta visibilidad no es independiente de la mirada y de la propia construcción social (Nogué, 2007) que a su vez se materializa en redes heterodoxas y en paisajes muchas veces ignorados, desconocidos y de localización difusa, que transgreden la trama formal de la ciudad como mera expresión de los potenciales económicos y que, capa sobre capa, a través del flujo del tiempo, se constituyen en patrimonio social intangible.

Una respuesta posible al problema de leer y actuar sobre estas complejidades la otorga la construcción eidética del paisaje hídrico urbano, que fiel a su origen, supone una 
mirada para nada inocente; se trata de un ejercicio de representación que no es una descripción neutral de lo que existe y que se aleja de la inercia de la representación objetiva, y por lo mismo, pasiva (Corner, 1999, p. 153). La construcción eidética del paisaje hídrico urbano podría constituirse entonces en el campo operacional donde se podría producir teoría y práctica de paisaje (Magini et. al., op.cit.) al tiempo que recoge también las complejidades urbanas de la sostenibilidad.

\section{Metodología}

La lógica operativa para la construcción eidética de los paisajes hídricos en este trabajo se compone de tres fases. La primera de ellas se refiere a la lectura del paisaje hídrico a través de la determinación de las cuatro capas de factores que inciden en la configuración del paisaje hídrico urbano en el caso estudiado. La segunda fase se trata de la determinación de los elementos tangibles e intangibles que construyen el paisaje hídrico y que se revelan en el recorrido perceptual del lugar investigado a través de la deriva psicogeográfica y el walkscape.

La tercera fase se trata de la ordenación de los elementos que constituyen el paisaje hídrico a través de la construcción de una matriz de componentes espaciales, obtenidos del lugar en estudio y que caracterizarán el paisaje hídrico urbano particular que se ha estudiado.

\section{Fase uno}

Se trata de un estudio diagnóstico e investigación de la configuración gráfica y espacial del espacio público que genera Paisaje Hídrico Urbano en un contexto en el que la sustentabilidad pasa a ser una directriz ineludible en la configuración social (cohesión, identidad, cultura, etc.), el desarrollo económico (economías locales, ahorro y eficiencia urbana, energía, movilidad, etc.) en un marco ambiental (naturaleza, biodiversidad, inundaciones, contaminación de riberas, etc.) determinado por nuestras ciudades.

Como factores perceptivos del paisaje hídrico singular se construye la sistematización de la información del lugar en tres grandes contenedores espaciales que configuran el paisaje: Waterscape, Paisaje Antrópico y Escena Urbana.

Waterscape: Se trata de la estructura profunda, la red geográfica y ecosistémica que prevalece y constituye la base de intervención antrópica, urbana. Este paisaje se 
corresponde con una organización vertical y morfológica natural con la preponderancia del agua como configuradora de las formas mismas del espacio. Como soporte de expresión gráfica se elaboran perfiles transversales y longitudinales que expresan la información específica de cada situación o caso seleccionado en dimensiones urbanas, pendientes naturales y/o construidas, la vegetación de ribera, del interior y sus posibilidades de conexión y/o acceso al cauce natural del río.

Paisaje Antrópico: Entorno construido en el tiempo planificado o desregulado por la acción urbana público/privada de usos, actividades y normas sobre el cauce y su entorno urbano (Nogue, 2007). Se configura como una organización horizontal del espacio y de las densidades construidas donde se encuentran algunos conceptos teóricos contemporáneos como junkspace, generic city, o urbanalización (Muñoz, 2007). Este paisaje se corresponde con una estrategia evolutiva del espacio como un inventario de capas de información temporal, donde los cambios en las estructuras a largo plazo condicionan la dinámica de superficie en el corto plazo. Como soporte de información se elaboran distintas cartografías en planta del lugar que muestran el trazado urbano tangible e intangible de la construcción social de la ciudad.

Escena Urbana: Se trata de una estructura fluida, superficial y dinámica que configura lo singular, la poética de la ciudad y la naturaleza, un paisaje más su hábitat, lo tangible y lo intangible, como un despliegue de la diversidad visual, ambiental, social y económica característica de una ciudad. Este paisaje Hídrico Urbano se corresponde con las vistas panorámicas o cuencas visuales que señalan las características físicas, geográficas y de biodiversidad encontradas, a la vez que posibilitan una lectura histórica de las huellas culturales trazadas en el lugar; demuestran las características sociales implícitas y los flujos intangibles que modelan la construcción urbana de este espacio.

Los conceptos de complejidad y compacidad (Rueda, 2010), son los dos ejes más espacializables y configuradores de paisaje urbano de los cuatro ejes esenciales para una ciudad más sostenible (complejidad, compacidad, eficiencia y cohesión).

La compacidad, indica el grado de contacto, intercambio y comunicación, que son la esencia de la ciudad. La complejidad, hace referencia a un tejido heterogéneo e interrelacionado, y supone aumentar la mixtura de usos y funciones urbanas, lo que permite un acceso a la ciudad sin restricciones y supone una mayor relación entre individuos portadores de información (Rueda, op. cit.). Se trata de la conservación y revaloración de los rasgos diferenciadores del lugar, que van a ser una cuestión clave para proyectar con la naturaleza (McHargh, 2000) y así dotar de una identidad 
a las ordenaciones y establecer una empatía de los residentes con su barrio. La sostenibilidad de las ciudades pasa necesariamente por la escala local y así también se habla de la necesidad de una ciudad con mezcla de actividades y gentes; entonces resultan necesarios los espacios públicos de calidad, con mezcla de posibilidades, por disponer de diversas opciones micro climáticas, físicas y de uso, y que permiten al

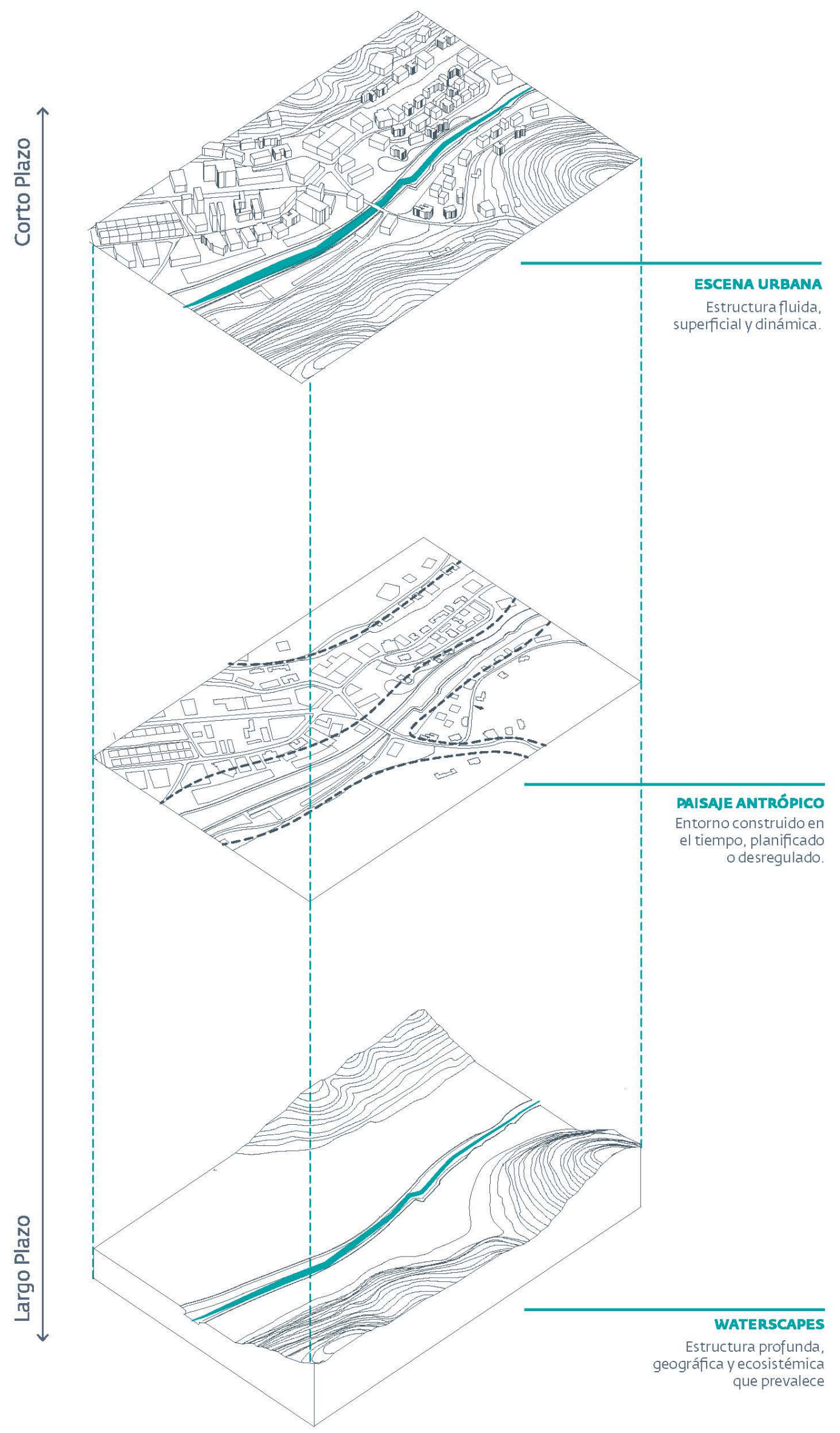

Figura 1. Las capas de los factores perceptivos del Paisaje Hídrico Urbano. Fuente: Paisaje Hídrico Urbano, Castillo C. et al, 2014. 
ciudadano emplearlos acorde a sus requerimientos. Así, desde la pequeña escala, una plaza o la ribera de un río por ejemplo, se pretende poner de manifiesto la importancia de la creación y recuperación de la ciudad con diversidad de posibilidades en su uso (Urrutia Del Campo, 2014). Si la sostenibilidad global ha requerido de la sostenibilidad de las áreas urbanas, la sostenibilidad de las ciudades pasa necesariamente por la rehabilitación del suelo urbano consolidado en su integración con el medio natural (Higueras, 2009).

\section{Fase dos}

Se trata de un estudio perceptivo de la configuración del paisaje hídrico que se resuelve a través de la determinación de los elementos tangibles e intangibles presentes en este paisaje. La configuración de estos elementos se determina por la interacción de los elementos existentes en el paisaje y quien recorre el lugar. Se trata de levantamiento de información primaria que servirá para construir los componentes en la tercera fase. Estos elementos se encuentran en disposición multiescalar, abarcando diferentes temporalidades.

\section{Fase tres}

Se trata de la ordenación matricial de los elementos encontrados para constituir componentes. Estos componentes contienen la información obtenida en las dos fases anteriores. Su ordenación responde a la configuración particular del paisaje hídrico estudiado.
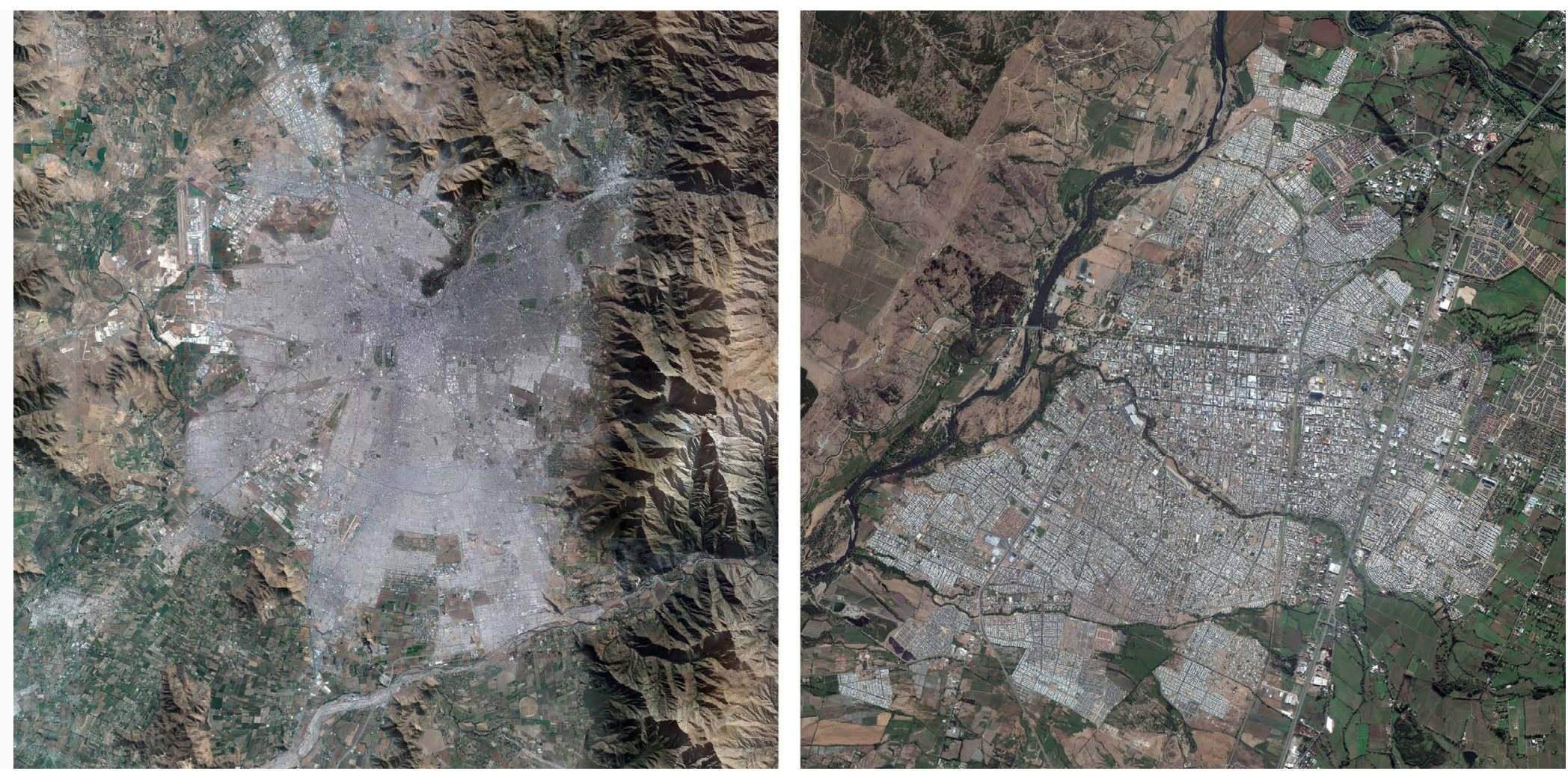

Figura 2. Las ciudades de Santiago (izquierda) y Talca (Derecha). Fuente: Landsat-Google Earth, 2015. 


\section{Casos de Estudio: Las ciudades de Santiago y Talca ${ }^{3}$}

Una condición de interés en estos casos de estudio radica en la posibilidad de observar los paisajes hídricos urbanos de una ciudad capital - metropolitana (Santiago) y compararlos con los que se pueden observar en una ciudad intermedia (Talca).

\section{Tres casos del mapocho urbano en Santiago de Chile}

Con la selección de tres casos de cruce o encuentro del trazado urbano con el río Mapocho, en Santiago de Chile, se pretende dar una visión articulada de la complejidad de los procesos hídricos que se desarrollan en la ciudad y del rol crucial que el paisaje hídrico urbano puede tener en la conformación de lugares e identidades particulares. Se estima que el estado y la configuración actual del espacio público y natural en una ciudad ha sido el reflejo de la sociedad que lo habita y lo construye en el tiempo. Para esta investigación, y desde la percepción del paisaje hídrico, se configuran los factores Waterscape, Paisaje Antrópico y Escena Urbana; lo anterior se complementa desde la sustentabilidad urbana con el reconocimiento de la compacidad en la planificación y trazado urbano junto a la complejidad en la morfología y tipologías edificadas en cada caso. Se pretende una lectura integral a través de los paisajes hídricos estudiados, reconociendo su modalidad pro integración o negación de un desarrollo urbano sostenible, señalando su ubicación en relación al paradigma de urbanización a través del reconocimiento singular de las partes que lo configuran. Para ello se complementa

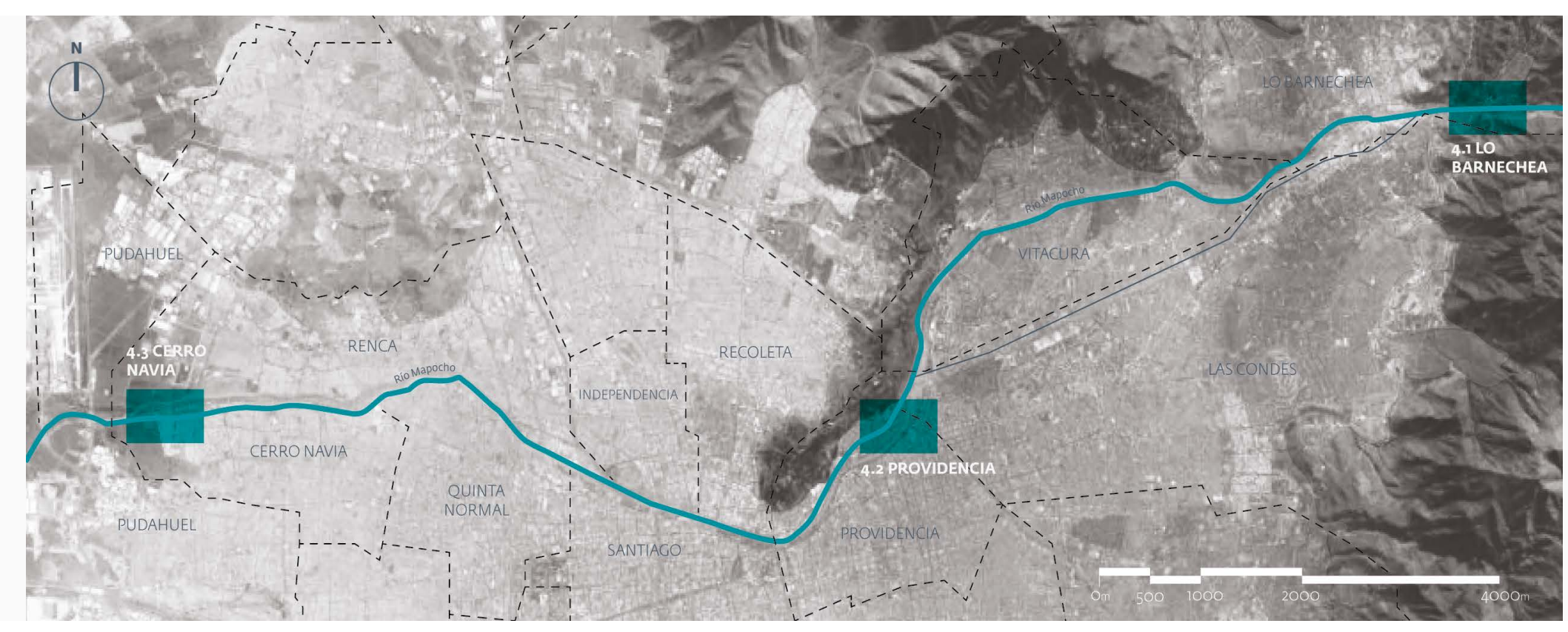

Figura 3. Tres casos urbanos del Rio Mapocho en Santiago de Chile. Fuente: Paisaje Hídrico Urbano, Castillo C. et al, 2014.

3 Los casos de estudio han sido elegidos en razón de la oportunidad ofrecida por la Universidad Diego Portales de Santiago y la Universidad de Talca, de la ciudad del mismo nombre, ambas en Chile, para desarrollar parte del estudio a través de la puesta en marcha de workshops con estudiantes de la carrera de arquitectura. Es así como, durante el año 2014 y el primer semestre de 2015 se inició el estudio del paisaje hídrico del río Mapocho en Santiago y del río Claro, estero Piduco y canal Baeza en la ciudad de Talca. 
la información técnica con entrevistas al poeta chileno Raúl Zurita, quien aporta una mirada lateral y en paralelo a la percepción y registro de la configuración temporal del paisaje hídrico urbano.

Los casos se corresponden con la entrada del río Mapocho a la ciudad (Caso 1: Lo Barnechea. Coordenadas: $33^{\circ} 21^{\prime} 44.39^{\prime \prime}$; 70²9'35.69"O), con un punto consolidado en el centro de Santiago (Caso 2: Providencia. Coordenadas: $33^{\circ} 24^{\prime} 57.37^{\prime \prime}$; $70^{\circ} 36^{\prime} 27.78^{\prime \prime} \mathrm{O}$ ) y un punto final en la periferia urbana oeste, cuando el río sale de la ciudad (Caso 3: Cerro Navia. Coordenadas: $33^{\circ} 24^{\prime} 49.56^{\prime \prime}$; 7046'10.49”O). La observación se compone tanto del registro audiovisual documental como de las láminas que mapean el paisaje en su configuración de planta y perfil urbano.

El Caso de Providencia, es el que mejor muestra el carácter secundario que tiene el río en el Santiago actual y también cómo ha sido reemplazado por las infraestructuras de flujo urbano que enfatizan la idea de que todas las ciudades son básicamente sistemas hidráulicos aunque lo que circule por ellos no sea precisamente agua (Delgado, 2014).

Las palabras del poeta chileno Raúl Zurita:

"Pero la sensación es que es un río que está agonizando, en sus últimos estertores, por lo menos en lo visible. No entiendo por qué nos apegamos a una figura que existe solo en la palabra. Santiago, como toda capital sudamericana, tiene una fisonomía sobre la que ya no hay vuelta atrás. Se preservan algunos barrios, que ojalá se preserven,

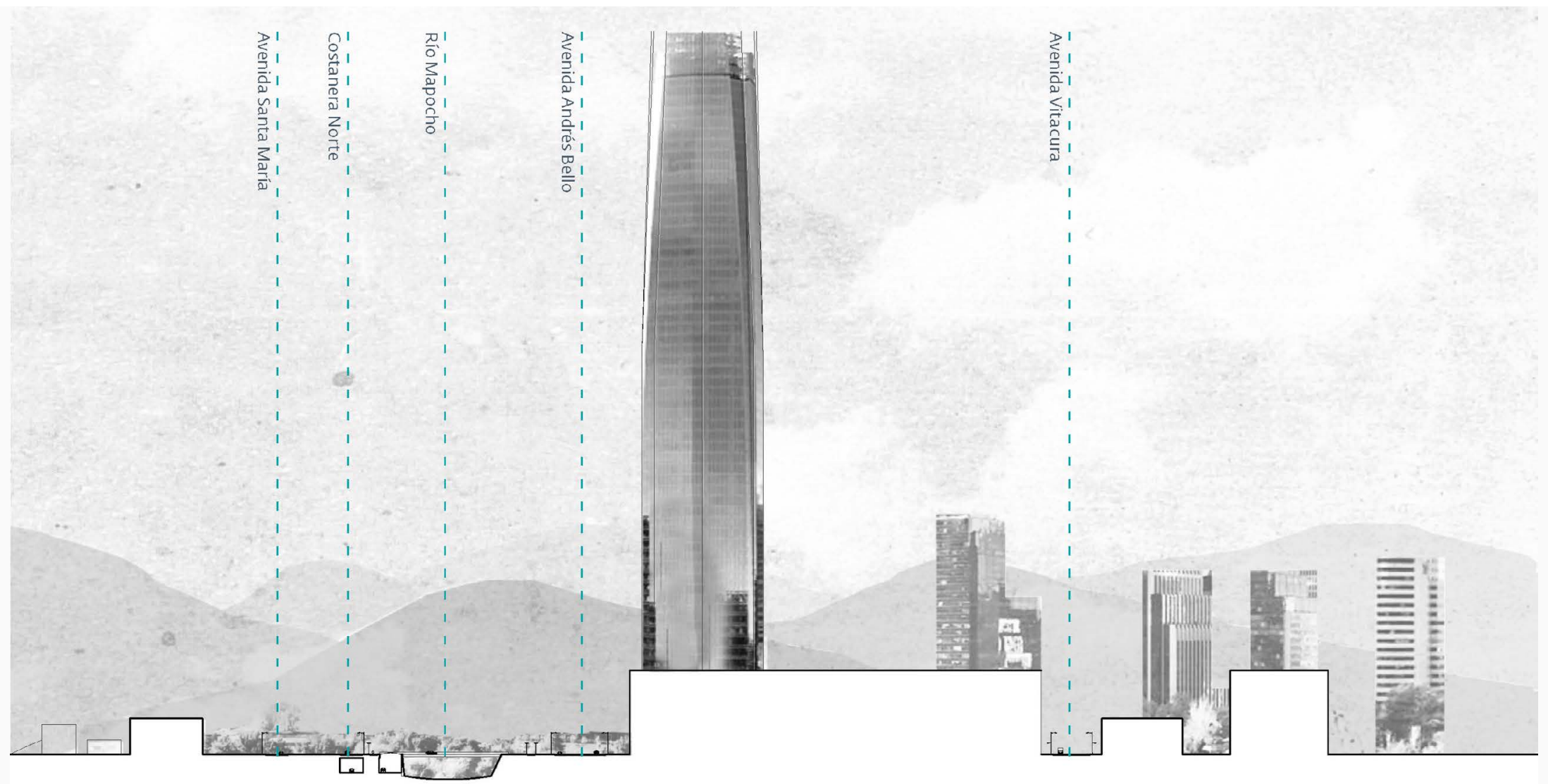

Figura 4. Perfil Urbano del rio Mapocho en Providencia. Fuente: Paisaje Hídrico Urbano, Castillo C. et al, 2014, p. 20. 
pero la construcción en altura ya se largó. Entonces me parece que hay una especie de romanticismo, que yo no entiendo mucho, de pretender mantener enclaves históricos que prácticamente son falsos, que no existen. Yo creo que eso partió cuando se murió el puente Cal y Canto. Ahí comienza la despedida del río. Mantenerlo tal como está no es una fidelidad a nada porque ya sufrió todos los embates que sufren los ríos con la

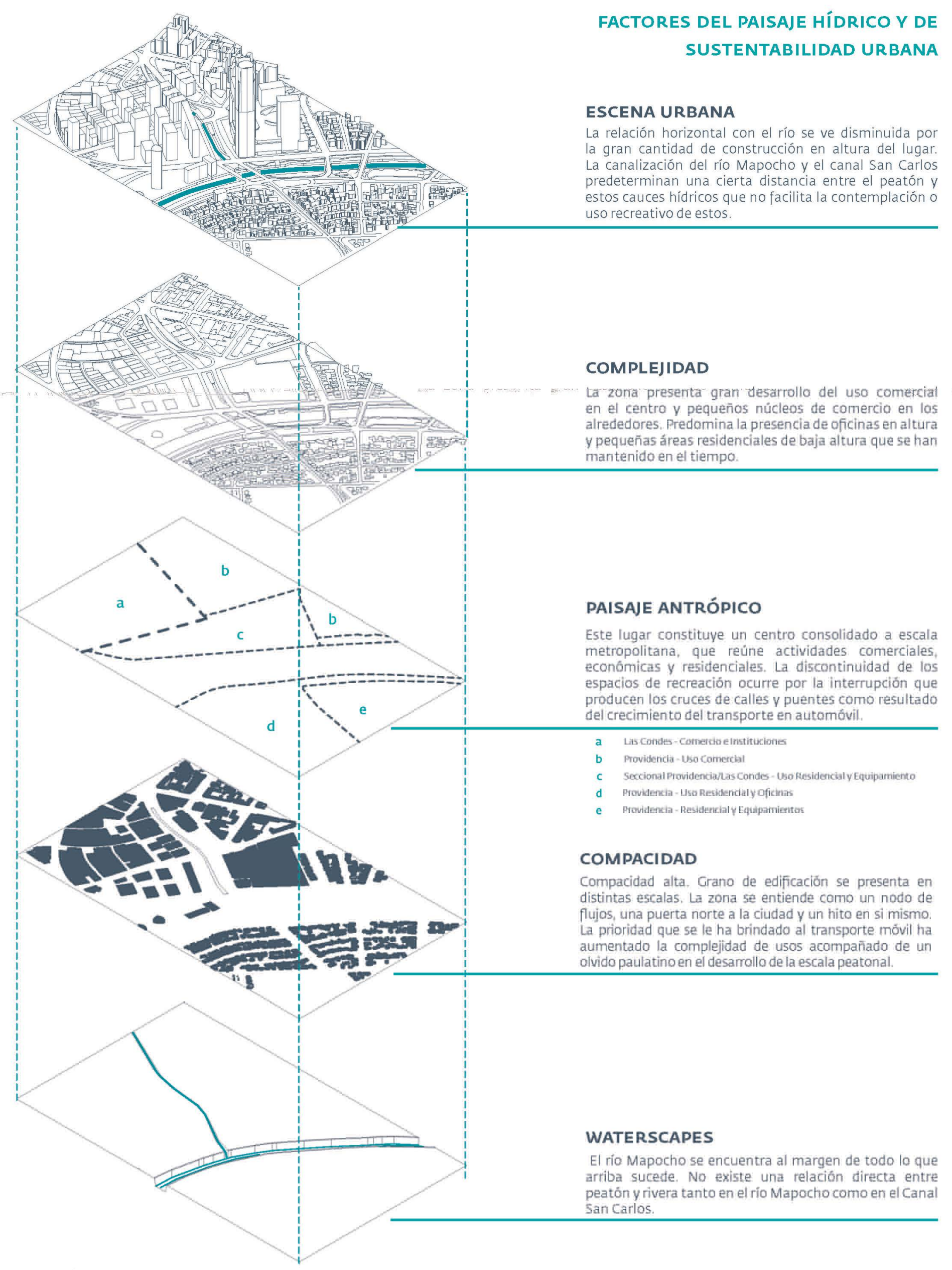

Figura 5. Factores del Paisaje Hídrico y de Sustentabilidad Urbana, Caso Providencia. Fuente: Paisaje Hídrico Urbano, Castillo C. et al, 2014, p. 17. 
modernidad, y para este fue bastante fatal. Entonces es imposible volver a un estado adánico, por así decirlo, ver como fluye el río cuando no había prácticamente nada, el paraíso que tú pones...es imposible regresar a eso" (Castillo, 2014, p. 21).

Es el paisaje de las infraestructuras, es un paisaje constituido principalmente de hormigón, con un cauce altamente intervenido, nada más que una canalización, con la idea principal de contener. En este punto no se puede ni entrar ni salir del cauce (Boza Wilson, 2014). "Es un cauce tan delgado...es un hilo de agua que contrasta con los murallones, con todo el aparataje de defensa..." (Castillo, 2014, p. 21).

En este lugar, la vegetación y la presencia del agua se ven claramente disminuidos ante la presencia del borde y de la construcción urbana en los mismos. En términos de sensibilidad al agua, es uno de los puntos más insensibles de la ciudad o si se quiere mirar a la inversa, uno de los más dañados del cauce del río Mapocho en su parte urbana (Boza Wilson, op.cit.). Así, la escena urbana se estructura sobre una relación horizontal con el río disminuida por la gran cantidad de construcción en altura del lugar. La canalización del río Mapocho y el canal San Carlos predeterminan distancias entre el peatón y los cauces hídricos. La complejidad del lugar es relativa ya que existe un gran desarrollo, principalmente comercial, con predominio de oficinas en altura y pequeñas áreas residenciales de baja altura que han logrado permanecer.

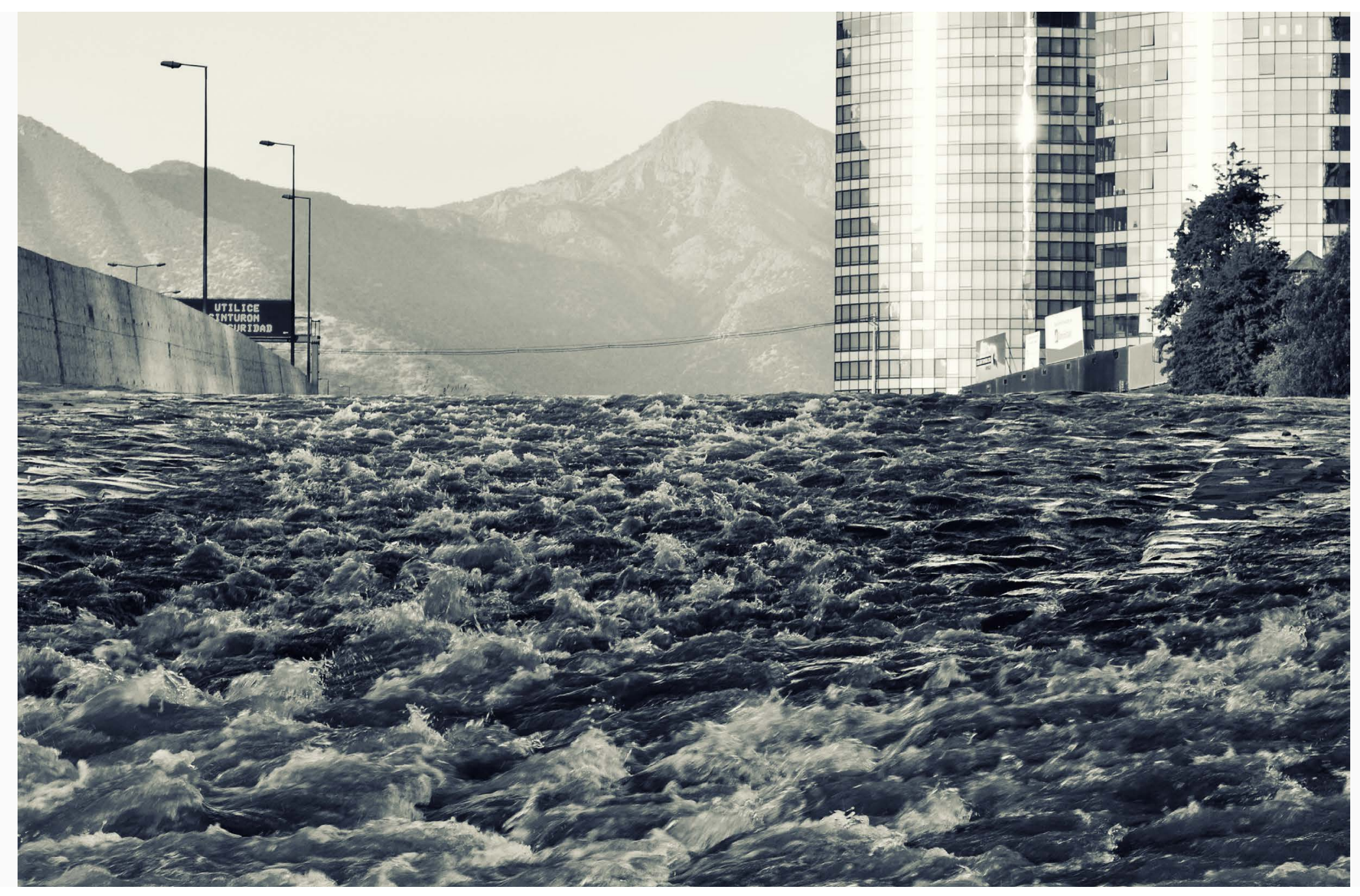

Figura 6. Paisaje Hídrico desde el río, Mapocho Urbano, Santiago de Chile. Fuente: Fotografía Cristian Boza Wilson, 2014. 
En consecuencia, tenemos un Paisaje Antrópico que corresponde a una centralidad consolidada de escala metropolitana, que reúne actividades comerciales, económicas y residenciales. La discontinuidad de los espacios verdes aumenta a raíz del aumento de la infraestructura que se le da al automóvil. La compacidad se puede describir como un grano edificatorio en distintas escalas, aún en proceso de transformación en tanto se trata de un nodo de flujos, un hito en sí mismo a raíz del implante de la torre más alta de la ciudad. Por otra parte, la prioridad que se le ha dado al automóvil ha comenzado a desarticular la red de escala peatonal. En cuanto a Waterscape, el río Mapocho se encuentra al margen de todo lo que sucede arriba. No existe una relación directa entre peatón y rivera, tanto en el río Mapocho como en el Canal San Carlos.

\section{Tres casos de la trama hídrica de la ciudad de Talca}

Para efectos de este trabajo, hemos considerado que la ciudad de Talca cuenta con tres escalas en relación con sus torrentes urbanos; la primera escala es la del Río Claro ${ }^{4}$ que bordea por completo la ciudad. El área de estudio, corresponde al tramo del Río Claro que bordea la zona urbana de la ciudad de Talca que se considera como límite (Toledo et. al., 2015). Luego tenemos la situación del estero El Piduco5 que divide a la ciudad en dos sectores (Norte-Sur). Y finalmente, tenemos la escala del Canal Baeza, que en su origen fue límite de la ciudad y cuyo curso fue modificado a su actual ubicación a fines

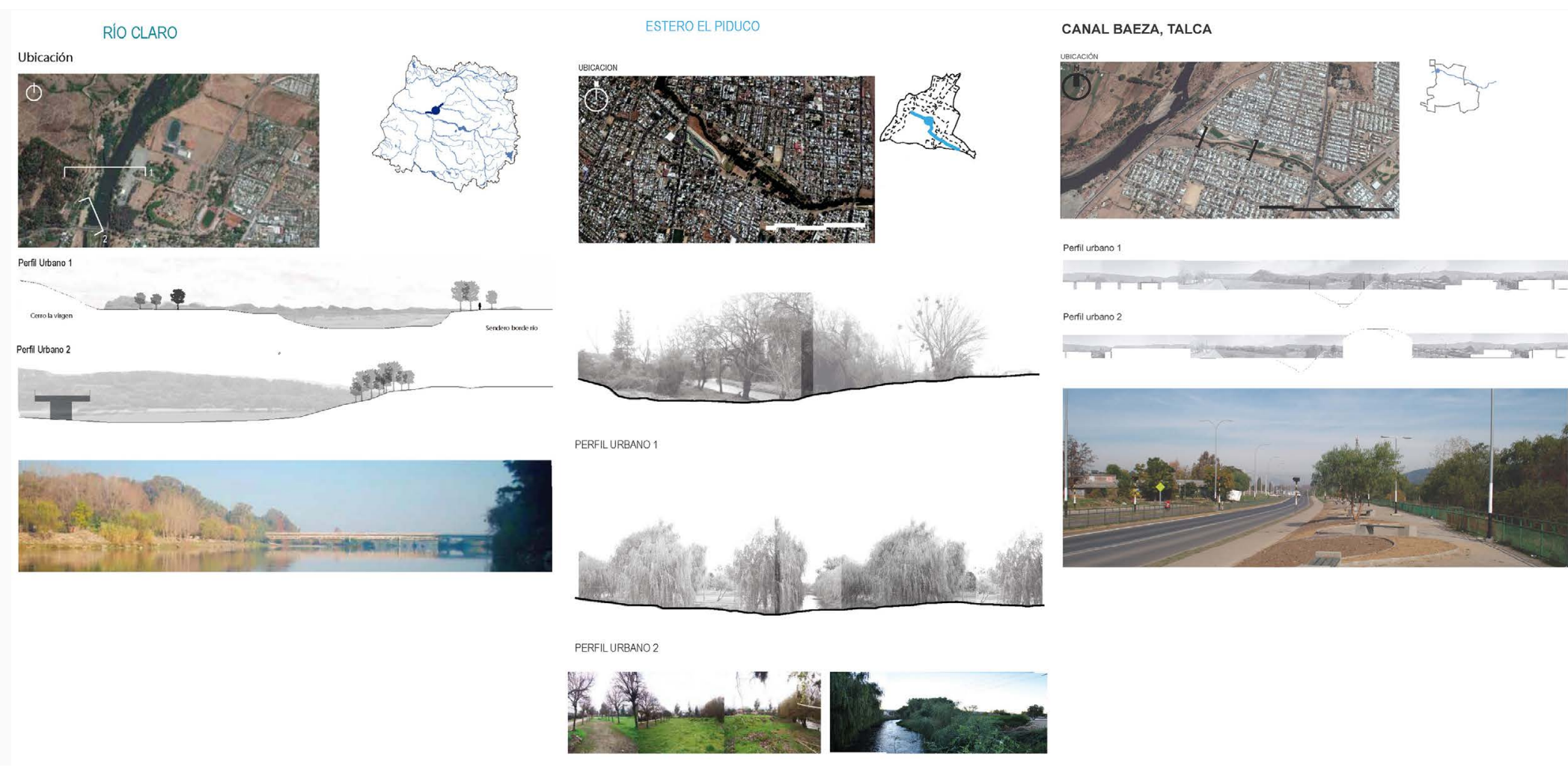

Figura 7. Torrentes urbanos en estudio en la ciudad de Talca. Fuente: Gaete y Olave; Toledo y Mellado; Macaya y Verdugo, Escuela de Arquitectura Universidad de Talca, 2015.

\footnotetext{
$4 \quad$ El Río Claro es un afluente del Río Maule que nace en el Parque Nacional Radal Siete Tazas. Atraviesa las comunas de Molina, Río Claro, Sagrada Familia, San Rafael y Talca.

5 El Piduco es un cordón biológico donde se encuentran diversas especies que conviven en un entorno endémico a lo largo de su extensión (Gaete et. al., 2015).
} 
de la década de los años 60, constituyéndose nuevamente como límite en la expansión urbana en su nueva localización (Macaya et.al., 2015).

En los tres casos de la ciudad de Talca se ha aplicado la metodología haciendo énfasis en la escala micro, sin perder la noción de relación multiescalar. Se han determinado los elementos tangibles concretos o pre-existentes como las tres escalas de vegetación, arbórea, arbustiva y herbácea o rastrera que cubre algunos tramos del suelo añadiéndole una textura al paisaje que se va mezclando con las zonas de acopio de materiales de construcción, escombros y basuras. Todo ello va acompañado de elementos de infraestructura urbana y residencial que aparecen de manera esporádica en los bordes. También se han determinado elementos tangibles perceptuales que se pueden encontrar en situaciones informales que hemos denominado estancias. Se trata de lugaridades informales y pasajeras, que se caracterizan por apilamientos de piedras de tamaño importante y cartones dispuestos de alguna manera reconocible, huellas asociadas a bajadas informales a la orilla, diferencias en las texturas del suelo que varían de lo barroso a lo rocoso, etc.
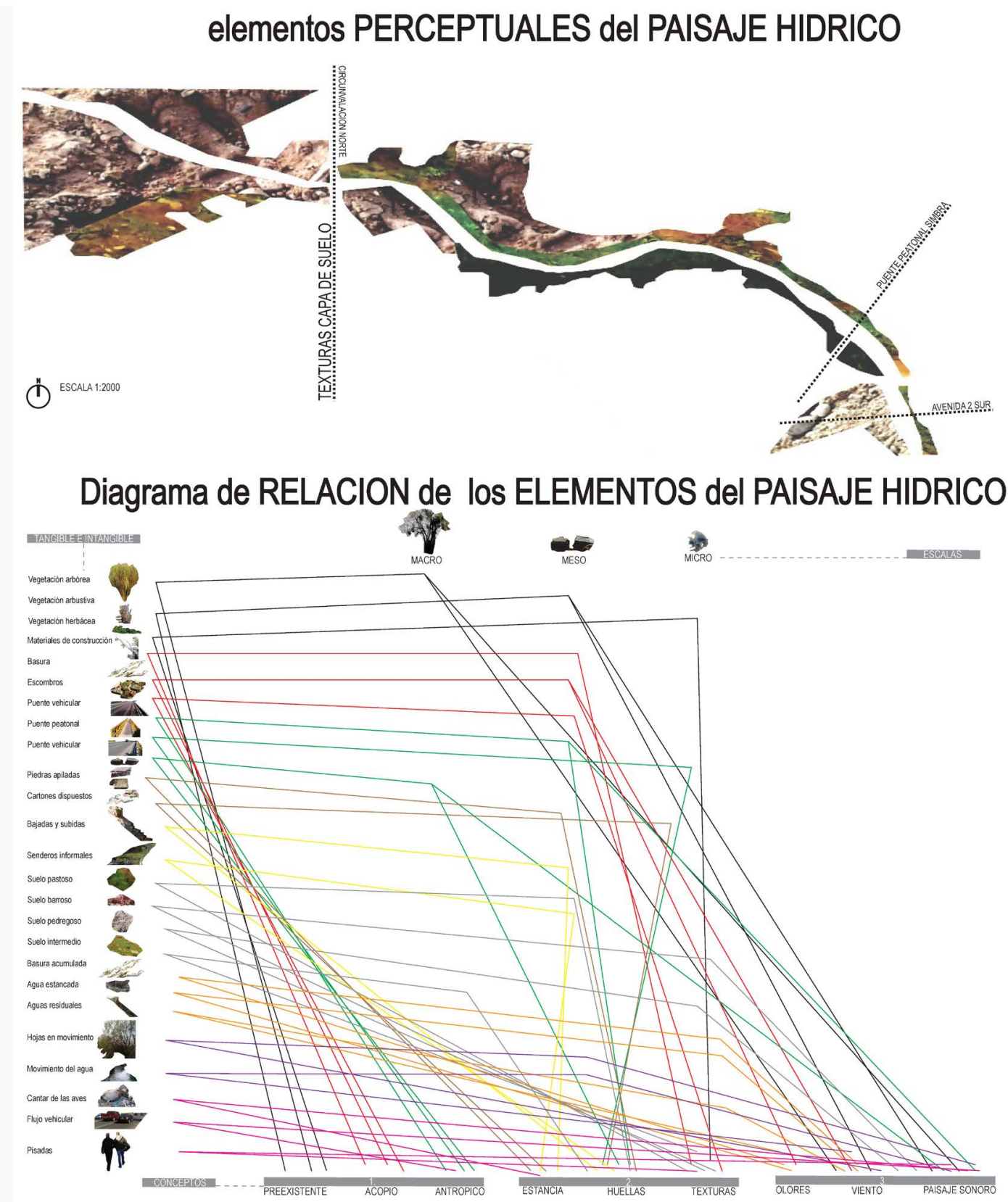

Figura 8. Elementos perceptuales del paisaje hídrico del Piduco. Fuente: Gaetey Olave, Escuela de Arquitectura Universidad de Talca, 2015. 
Entre los elementos intangibles se considera los distintos olores generados por las también diferentes condiciones del torrente en su recorrido, el viento que se hace evidente en la caída de hojas que genera una nueva capa y textura en los suelos del borde.

Vinculando todo, encontramos el paisaje sonoro que resulta de la mixtura del sonido del follaje, las aves, el flujo vehicular, los pasos en las diferentes calidades del suelo y al tercer paisaje, aquel que resurge cuando el ser humano desaparece (Clément, 2007 p. 6), una especie de subproducto del proceso urbano (Gaete et. al., 2015).

Todos estos elementos se relacionan en un gráfico cuyo eje vertical son los elementos que componen el paisaje hídrico (tangibles e intangibles) y el eje horizontal son los conceptos relacionados a dichos elementos. La finalidad de este gráfico es entrever algún punto de relevancia donde confluyen más de un elemento del paisaje hídrico urbano para construir lo que hemos llamado Componentes Perceptuales del Paisaje Hídrico, en este caso, del Estero El Piduco. Estos componentes los podemos clasificar en:

- Preexistentes: se combinan elementos de contexto, cauce hídrico y la vegetación en tres escalas macro, meso y micro. Un muro verde separa la urbe del tercer paisaje dejándolo concentrado en sí mismo.

\section{Componentes Perceptuales del Paisaje Hídrico}

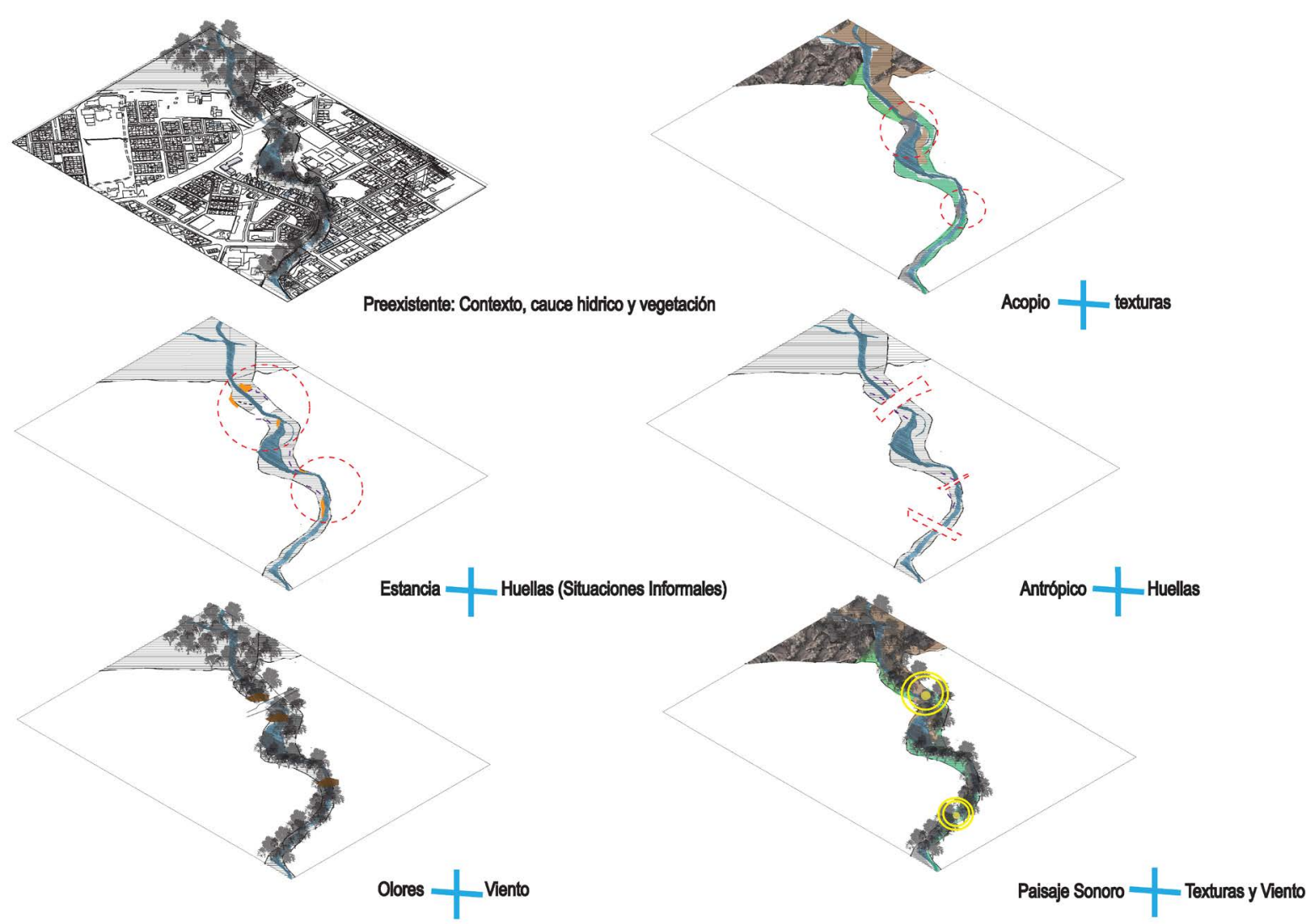

Figura 9. Componentes del paisaje hídrico del Piduco. Fuente: Gaete y Olave, Escuela de Arquitectura Universidad de Talca, 2015. 
- Acopio más texturas: variaciones de las capas del suelo donde inciden algunos acopios de materiales de construcción y escombros.

- Estancia más huellas (Situaciones Informales): lugares denominados de estancia; se generan a partir de algunos elementos sígnicos como piedras apiladas. Se hacen visibles ciertos senderos Informales hacia el cauce hídrico.

- Antrópico más huellas: puentes peatonales, puentes vehiculares, y la infraestructura vial a la que se vincula la aparición de ciertos senderos informales que van al encuentro del cauce.

- $\quad$ Olores más viento: se trata de un gráfico más bien perceptual en donde se hacen presentes algunos focos claros en ciertos puntos, la humedad existente en el ambiente, el movimiento del agua y el desplazamiento de olores en algunas partes del tramo.

- Paisaje sonoro más texturas y viento: gráfico perceptual de los elementos intangibles, y la mezcla, como las aves, el sonido del flujo vehicular, las pisadas de las distintas capas de suelo, acompañadas del movimiento del agua al recorrer el tercer paisaje y el movimiento de los follajes por efecto de los vientos. (Gaete et. al., 2015)

\section{Conclusiones: Paisaje hídrico para la sostenibilidad urbana}

Este estudio busca ofrecer una metodología para describir y determinar los componentes del paisaje hídrico urbano que se construye en la vinculación de la ciudad con su torrente urbano, a través de la relación de componentes particulares del sistema hídrico de cada lugar.

El objetivo es poner en relieve la relación del paisaje perceptivo con los problemas y realidades medio ambientales, productivas y de planificación del espacio urbano relacionado con el torrente urbano y visibilizar lo que se ha dejado fuera de foco, para superar la parcialidad e ir más allá de la trama formal de la ciudad como mera expresión de los potenciales económicos para incorporar los valores del patrimonio social intangible. 


\section{Ubicación de los componentes de un Paisaje Hídrico.}
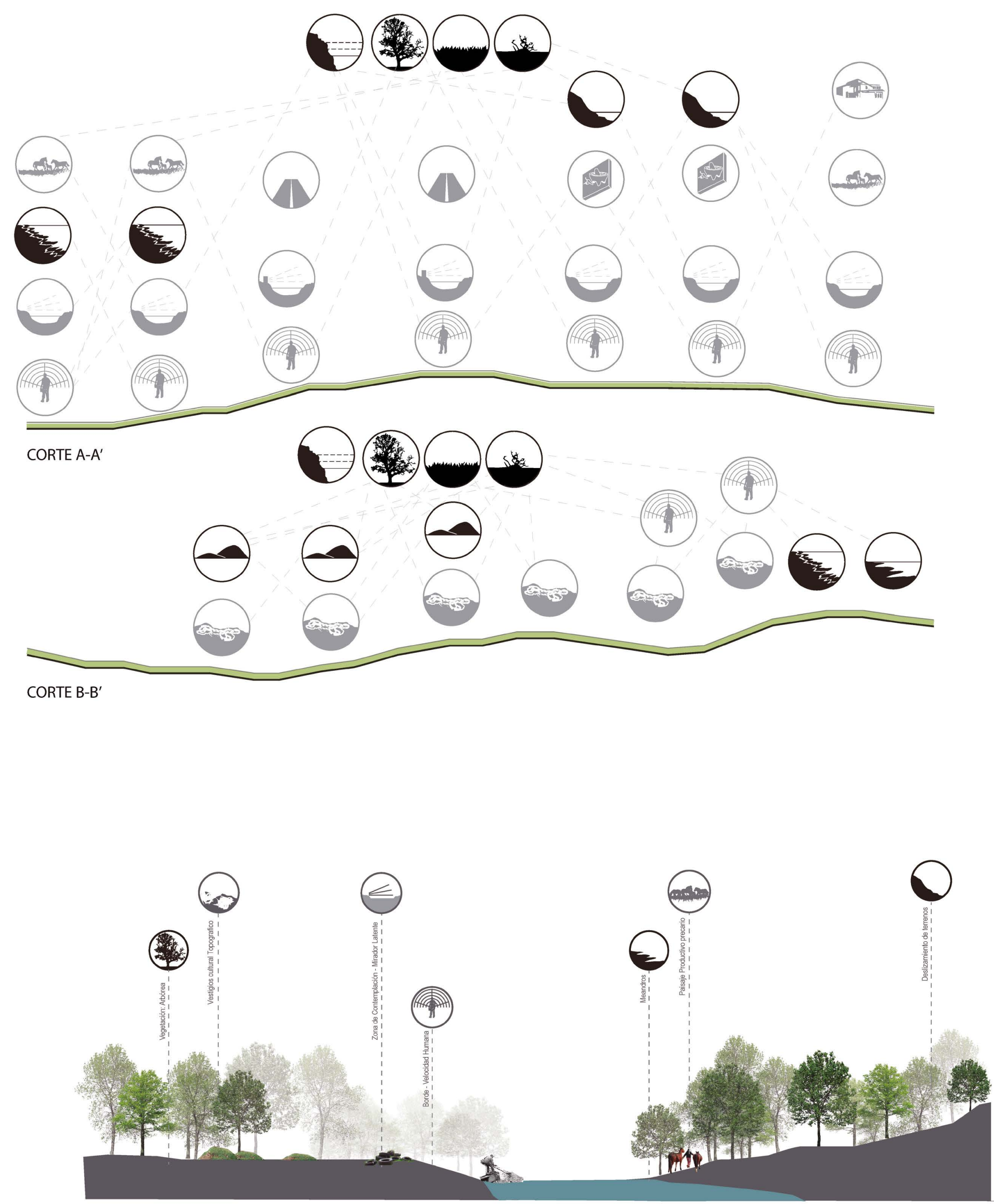

Figura 10. Localización de componentes del paisaje hídrico del Río Claro. Fuente: Toledo y Mellado, Escuela de Arquitectura Universidad de Talca, 2015. 
Los casos estudiados reflejan el contraste de lo que significa la concentración urbana en el Chile contemporáneo. Tenemos un ejemplo obtenido en una de las nuevas centralidades de la capital de Chile y lo hemos puesto frente a otra muestra obtenida en uno de los torrentes de una de las ciudades intermedias de la Región del Maule, al sur de Santiago. Salta a la vista de inmediato la desproporción entre los paisajes estudiados. Sin embargo, ambos pueden ser leídos con las mismas herramientas metodológicas propuestas a fin de determinar en una fase posterior algunos umbrales en la disposición de los elementos estudiados a la luz de la sostenibilidad urbana.

\section{Proyecciones e intenciones}

Este avance para delinear el Paisaje Hídrico para una ciudad más Sustentable, deja una serie de constataciones e indicadores de la situación del torrente urbano en el caso de dos ciudades chilenas en la actualidad, así como una serie de reflexiones que fortalecen nuestra idea de que no se puede mirar la ciudad ni sus componentes de manera parcial y sin complejidad. Esto nos permitirá avanzar en la búsqueda de la estructura de variables interconectadas que a su vez nos permitan definir el nivel superior e inferior de tolerancia del sistema que subyace en el Paisaje Hídrico para intentar prever la patología y la disfunción del sistema. Es nuestro primer avance para comprender un sistema que se construye a partir del trazado que ha hecho el agua.

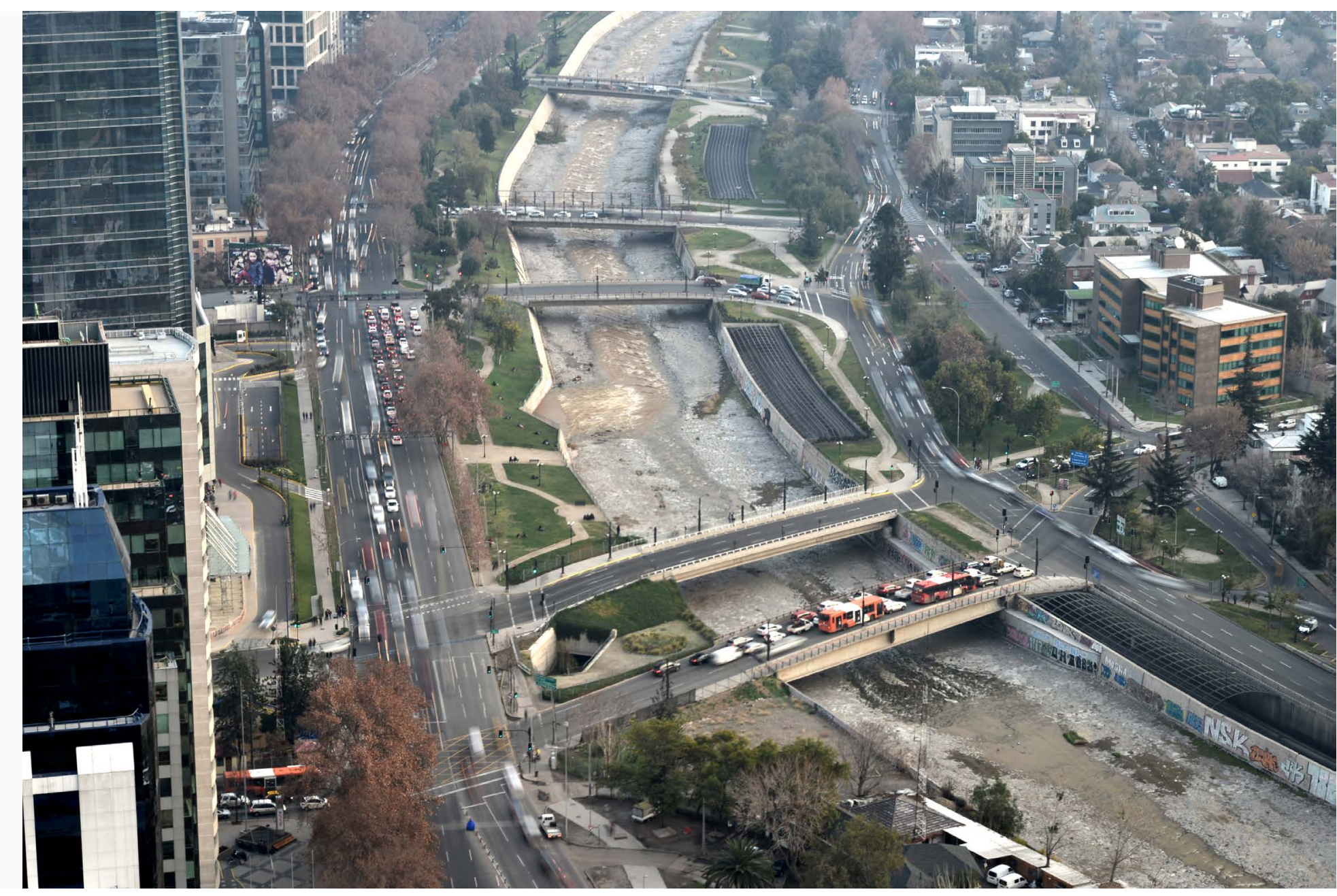

Figura 9. Componentes del paisaje hídrico del Piduco. Fuente: Gaete y Olave, Escuela de Arquitectura Universidad de Talca, 2015. 
Santiago de Chile es una ciudad al pie de la montaña, en consecuencia, la ciudad toda se ha construido sobre trazas hídricas que son parte sistémica de una cuenca hidrográfica mayor. Talca es una ciudad estructurada sobre una red de canales. Reconocer y entender el paisaje de la ciudad construido sobre el paisaje del agua en el soporte territorial resulta indispensable para la sostenibilidad de nuestro propio paisaje hídrico urbano y debiera ser recogido en los instrumentos de planificación.

Asimismo, este trabajo plantea un método de análisis de los Paisajes Hídricos Urbanos que se proyecte sobre los demás paisajes hídricos del país a fin de establecer una matriz comparativa de estas complejidades para situar los umbrales donde se podrían producir las patologías antes de que ocurran o, como en el caso de la mayoría de nuestros paisajes hídricos, poder delinear las bases de actuación a fin de dialogar con los proyectos de futuro para incluir estos parámetros como elementos de sostenibilidad en los instrumentos de planificación urbana tal y como lo requiere la nueva Política Nacional de Desarrollo Urbano de Chile.

\section{Referencias}

Abalos, I., (2005). Atlas Pintoresco Volumen 1: Los Viajes. Barcelona, España. Gustavo Gili. Ascher, F., (2004). Los Nuevos Principios del Urbanismo. Madrid, España. Alianza Editorial.

Boza Wilson, C., (2014). Riverfront de Torrente Urbano. Levantamiento del paisaje hídrico del río Mapocho urbano desde su cauce para el desarrollo de una ciudad más sensible al agua. Tesis para optar al grado de Magister en Territorio y paisaje, Facultad de Arquitectura, Arte y Diseño, Universidad Diego Portales, Santiago. Chile.

Brundtland, G., (1989). Our Common Future, From One Earth to One World. United Nations, World Commission on Environment and Development. New York. USA. Recuperado de http://www.un-documents.net/our-common-future.pdf

Castillo, C.; Del Castillo, M.; SaelzerMoller-Holtkamp, F. y De Pablo, J., (2014). Dossier 180 - 02: Paisajes Hídricos Urbanos - Santiago de Chile, Río Mapocho, Revista 180, 34, ISSN: 0718-2309, FAAD UDP. Santiago. Chile. Editorial Salviat.

Clément, G., (2007). Manifiesto del Tercer Paisaje. Barcelona. España. Gustavo Gili. 
Corner, J., (1999). Recovering Landscapes. New York, USA. Princeton Architectural Press.

De Landa, M., (2012). Mil Años de Historia no lineal. Barcelona. España. GEDISA.

Fariña, J. (2010). Espacios Urbanos Virtuales. El blog de José Fariña: Urbanismo, Territorio y Paisaje. Recuperado de: http://elblogdefarina.blogspot.com/

Gaete, S. y Olave, C., (2015). Configuración de la huella perceptual de un paisaje hídrico. El caso del estero el Piduco, Talca. Chile. Escuela de Arquitectura Universidad de Talca. Talca, Chile.

Higueras, E., (2009). Buenas prácticas en arquitecturayurbanismo para Madrid:Criterios bioclimáticos y de eficiencia energética. Edición Área de Gobierno de Urbanismo y Vivienda del Ayuntamiento de Madrid. ISBN: 978-84-7812-718-4. Madrid. España.

Jacobs, J., (2011). Muerte y vida de las grandes ciudades. Salamanca. España. Swing.

Louiset, O., (2001). "Les Villes Invisibles". L'Information Géographique, 65 (3), 219-233. Université de Lyon. Lyon. Francia.

Mc Harg, I, (2000). Proyectar con la Naturaleza. Barcelona. España. Gustavo Gili.

Macaya, N. y Verdugo, L., (2015). El entorno público de un paisaje hídrico, Canal Baeza. Talca. Escuela de Arquitectura Universidad de Talca. Talca, Chile.

Magrini, C. y Pedraza, P., (2013). Antipostales, un corte sociográfico de Santiago, MTP, FAAD, Universidad Diego Portales, Santiago, Chile. Recuperado de https:// antipostalesdesantiago.wordpress.com/marco-teorico/

Mostafavi, M. y Gareth D., (2013). Ecological Urbanism. Harvard University Graduate School of Design - Zürich, Zwitzerland. Lars Müller Publishers.

Munford, L., (1960). La ciudad en la historia. Buenos Aires, Argentina. Infinito.

Muñoz, F., (2007). "Paisajes Aterritoriales, Paisajes en Huelga” en J. Nogué (Ed.). La Construcción Social del Paisaje, pp. 293-313. Madrid. España. Biblioteca Nueva.

Naredo, J., (2000). “Ciudades y crisis de civilización”. Documentación Social, (119), 1337. 
Novotny, V. y Brown, P., (2007). "Cities of the Future: the fifth paradigm of urbanization". En: Cities of the Future: towards integrated sustainable water and landscape management. Londres. U.K. IWA Publishing.

Nogue, J., (2007). La Construcción Social del Paisaje. Madrid. España. Biblioteca Nueva.

Rueda, S., (1994). "El ecosistema urbano y los mecanismos reguladores de las variables autoregenerativas”. En: Ciudad y Territorio: Estudios Territoriales, 2 (100-101), 251-263. Madrid. España. Ministerio de Vivienda.

Rueda, S., (2010). "La ciudad compacta y diversa frente a la conurbación difusa". En: Abalos, I. (Ed.). De lo mecánico a lo termodinámico. pp.153-170. Barcelona. España. Gustavo Gili.

Tansley, A., (1935). "The use and abuse of vegetational concepts and terms". Ecology, $16(3), 284-307$.

Toledo, P. y Mellado, D., (2015). La Configuración Dual. Río Claro, Talca, Chile. Escuela de Arquitectura Universidad de Talca. Talca, Chile.

Urrutia, N., (2010). Clima, diseño y diversidad urbana en el uso de tres plazas de Madrid. CONAMA 10. Madrid. España. Recuperado de http://www.conama10.es/conama1o/ download/ files/CT\%202010/41038.pdf

Whiston Spirn, A., (1984). The Granite Garden: Urban Nature and Human Design. New York. USA. Basic Books.

Whiston Spirn, A., (1988). The Language of Landscape. New Heaven, USA. Yale University Press.

Whiston Spirn, A. (2011). w Recuperado de: http://www.annewhistonspirn.com/pdf/ spirn_ecological_urbanism-2011.pdf. 
Este artículo forma parte de:

\section{REVISTARQUIS}

Para más información, artículos, e instructivo de publicación, visite:

www.arquis.ucr.ac.cr/revistarquis.html 